\title{
Narrative review of women's health in Iran: challenges and successes
}

\author{
Hassan Joulaei ${ }^{1}$, Najmeh Maharlouei ${ }^{2}$, Kamran Bagheri lankarani $^{2}$, Alireza Razzaghi ${ }^{3}$ and Maryam Akbari ${ }^{*}$
}

\begin{abstract}
Background: In each society, the health of women in different periods may be endangered by an unequal distribution of resources, facilities, and gender prejudices. The present study evaluated the time trend of Iranian women's health between 1990 and 2013.
\end{abstract}

Methods: This narrative review includes an integration and descriptive summary of the existing evidence on trends and criteria of different aspects of women's health from social determinant point of view. The evidence was drawn from peer-reviewed, cross-national or large-scale studies, official sources of the Ministry of Health, reviews, and online scientific databases published between 1990 and 2013.

Results: The average life expectancy of Iranian women has increased from 44.15 years in 1960 to 75.75 years in 2012; in most deprived provinces of Iran, however, this criterion is about 67.3 years, and in the capital it is 75.8 years. In 2011, $43.37 \%$ of DALYS, $36.21 \%$ of YLL, and $1.92 \%$ of YLD were dedicated to women; these figures were $3.63 \%$ lower than they were in 2003. Although a significant reduction has occurred in maternal mortality rate, which dropped from 83 to 23 per 100,000 between 1990 and 2013, there is no equal distribution in maternal mortality across the country as manifested by the unfavorable conditions of border provinces $(S D=19.2)$. The prevalence of HIV/AIDS is an alarming health problem among Iranian females, increasing approximately $546 \%$ between 2007 and 2015. As for mental health, depression in women was ranked first among diseases in 2011 compared to a second place ranking in 2003. As regards social health, the delinquency of women has increased in recent years compared to men with women committing more crimes related to drugs and actions against virtue. The annual report of the United Nations for the gender gap index in 2013 ranked Iran as 130 among 136 countries (from 0.622 in 2000 to 0.584 in 2013).

Conclusion: Generally, over the last three decades, the health indices of Iranian women have grown in aspects of physical, mental, and social health. Remarkable differences can be seen among female health indices based on geographic location and in comparison with men. To promote an improved health status for Iranian women, the root causes of the discrepancies must be identified and a comprehensive national plan must be established.

\section{Background}

Globally, health is a precondition of the fulfillment of sustained development for which healthy humans play a key role. In this context, the health of women is of special importance, because they comprise half the world's population and play a pivotal role in family health and the development of societies. In other words, researchers believe that it is impossible to achieve the universal promotion of health and hygiene without women's health

\footnotetext{
* Correspondence: m.akbari45@yahoo.com

${ }^{2}$ Health Policy Research Center, School of Medicine, Shiraz University of

Medical Sciences, Shiraz, IR, Iran

Full list of author information is available at the end of the article
}

[1]. Health and its equitable distribution among various sectors of society have been principal themes of the World Health Organization, many other international agencies, and researchers over the past two decades. For this reason, women's health and its effective role in achieving the millennium goals of reduced mortality rates among mothers, gender equality, and the empowerment of women have drawn the special attention of the United Nations and its member states [2]. Women's health has been regarded as topmost among the activities and goals of health systems in communities and a benchmark for the development of countries. Nonetheless, according to the reports published by the United Nations Organization, 
women's health is vulnerable and deserves the special attention of policymakers [3].

According to World Health Organization reports, women are vulnerable for various reasons, such as their roles in family and society and various physiologic conditions including puberty, menstruation, pregnancy, and menopause. The female community is considered a high risk population because of the inequitable distribution of resources and opportunities, high poverty, hunger, and malnutrition rates, and gender discrimination against women [4]. The well-being of a community is assessed and monitored on the basis of its health status standard. In this context, the criteria representing the perspective of the female community and reflecting the existing health gaps in women's health include burden of disease, maternal mortality rates [5], repeated family violence [6], unequal job opportunities [7], poverty and disproportionate income [8], inaccessibility of educational facilities [9], intensive stress [10], and depression and isolation [7].

In Iran, like in many other countries, traditional differences exist between men and women in how they benefit from facilities [11]. In recent years, the Islamic Republic of Iran, like other states wherein rapid changes in social, economic and population dynamics have taken place, has undergone transformations which are considered as criteria for the successful assessment of the human development index. This is indicated by a growth rate of 0.443 in 1980 compared with 0.742 in 2012, which is equal to $1.05 \%$ or a global ranking of 76 [12]. Although this is an acceptable pace, its impact on reducing gender inequality remains unknown. The present study attempts to answer this question so as to provide concrete evidence to those involved in policy and decision making to aid the establishment of justice and reduce healthrelated inequalities. In addition, it explores the trends and criteria of different aspects of women's heath in the period 1990-2013.

\section{Materials and methods}

This study is a narrative review that includes an integration and descriptive summary of the existing evidence on trends and criteria of different aspects of women's health.

A search for literature from 1990 to 2013 was conducted in medical databases including PubMed, Medline, and Google Scholar and Iranian Farsi sources including Iran medex, SID, and MagIran. Based on the World Health Organization's definition, three aspects of health were considered: "physical health", "mental health", and "social health." The algorithm of the searching strategy for those aspects is. (Fig. 1)

Considering the above-mentioned aspects, and with focus on the outcome of each aspect, keywords used in the searches were "Iranian women" or "Iranian female" and "inequality", "life expectancy", "burden of diseases", "diabetes", "hypertension", "BMI", "physical activity", "maternal mortality", "HIV/AIDS", "STIs", "communicable diseases", "mental disorders", "suicide", "gender gap", or "violence." To further access some topics, other data sources such as the Statistical Center of Iran which is considered the country's most reliable statistical center, population and housing censuses, and the official reports of the Ministry of Health and Medical Education, the World Health Organization, and the United Nations Development Program were also accessed. The time period for the search was limited to 2000 and later. In this study, articles or documents published after 2000 were considered. Regarding the WHO definition; in this study equity is defined as the absence of any differences among groups of people that would be avoidable or treatable.

Because of the myriad health-related terms and extensive information about women's health in Iran, this report was confined to a limited number of terms related to ill health as the outcome of social and health systems

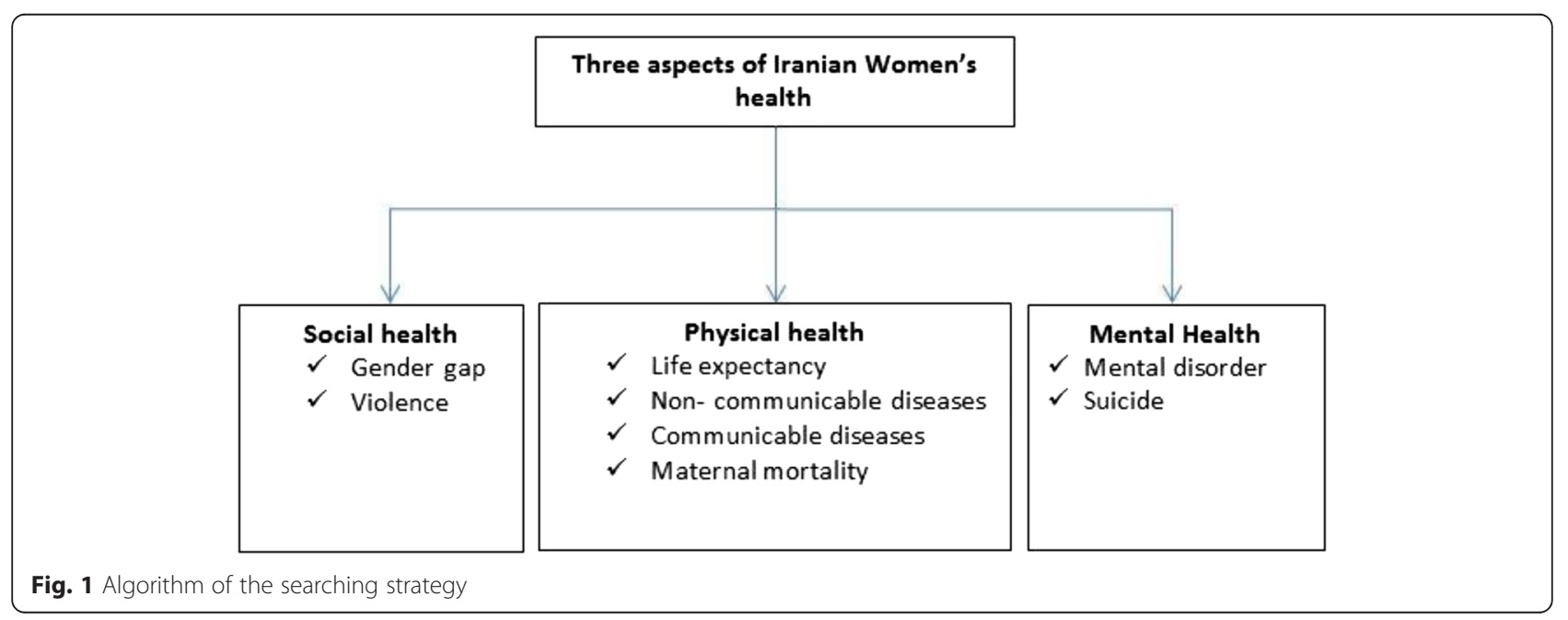


so that women's health in Iran could be more easily depicted.

\section{Results}

The results of the current study are presented in three parts, physical health, mental health, and social health indicators, as follows.

1) Physical health indicators Life expectancy: Life Expectancy (LE) is an important determinant associated with health-related results and is a so-called outcome indicator that plays an important role in public health [13]. Iranian women have higher LE than men $(77.8$ years $(75.3-80.2)$ vs. 71.6 years (68.5 - 74.6), respectively) [14]. The LE of women increased from 44.15 years in 1960 to 75.75 years in 2012. However, an important issue is the inter-provincial differences. While the LE of women in the most deprived province of Iran (Sistan and Baluchestan) is about 67.3 years, it is about 75.8 years in Tehran province, accounting for a difference of $12.6 \%$ among women [15].

Non-communicable diseases: Women shared $31.2 \%$ of all burden of disease (DALY ${ }_{S}$ ) of noncommunicable diseases (NCDs) in 2003 compared with $32.7 \%$ in 2011, an increase of about $4.8 \%$ [16]. The most prevalent diseases among Iranian females were cardiac ischemia, depressive disorders, and osteoarthritis (Fig. 2). The share of pregnancy and diseases related to childbirth in women was $7 \%$ in 2003 , which decreased slightly (0.4\%) to $6.6 \%$ in 2011 [17]. However, the principal cause of mortality in women was cardiac ischemia which caused $24.3 \%$ and $24.69 \%$ of deaths in 2003 and 2011, respectively [16]. The respective values for obesity and overweight with 9.33 \% DALY and disability with 11.87 YLD pose the highest associated risk factors for such diseases among Iranian women, followed by dietary risk with $9.19 \%$ DALY combined with $1.69 \%$ disability, high blood pressure with $7.72 \%$ DALY, and $83 \%$ disability [17]. A comparison of differences in risk factors associated with such NCDs between the two genders showed that $20.39 \%$ of men and $1.02 \%$ of women aged 15 to 64 years were smokers. The mean body mass indexes (BMI) were 25.66 in women and 24.22 in men. High blood pressure (systolic blood pressure $\geq 140$ and/or diastolic blood pressure $\geq 90 \mathrm{mmHg}$ ) presented in $16.12 \%$ of women and $16.07 \%$ of men. Moreover, $49.91 \%$ of women and $28.28 \%$ of men had low physical activity defined as $<600 \mathrm{MET}$-minutes/week [18]. Studies of elderly Iranian people showed that $17 \%$ of elderly men and $25 \%$ of elderly women suffer from heart disease and $42 \%$ of aged men and $46 \%$ of aged women have high blood pressure. The prevalence of hyperglycemia was reported as $63.6 \%$ of aged women and $42.6 \%$ of elderly men [19]. Study results revealed that the rate of osteoporosis in females is more than triple that of males (56.3\% vs. $16.7 \%$, respectively). The prevalence of pain involving weight-bearing and non-weight-bearing joints among Iranian women aged over 50 years is 6 times higher than their male counterparts. Smokers comprise $39 \%$ of the aged population, of which $38.9 \%$ are men and $29.1 \%$ are women [20]. Furthermore, reports indicated that physical problems (43\% vs. $39 \%$ ) and nostalgic and psychological problems (8.17\% vs. $3.25 \%$ ) are higher among aged women than elderly men [21].

Communicable diseases: HIV/AIDS has a growing trend in Iran. The number of people living with

\begin{tabular}{|c|c|}
\hline DALY 1990 & DALY 2010 \\
\hline Congenital anomalies & Low back pain \\
\hline Ischemic heart disease & Major Depressive disorders \\
\hline Forces of nature & Ischemic heart disease \\
\hline Lower respiratory infection & Road injury \\
\hline Major Depressive disorders & Congenital anomalies \\
\hline Preterm birth complications & stroke \\
\hline Low back pain & Iron deficiency anemia \\
\hline Diarrheal disease & Anxiety disorders \\
\hline Iron deficiency anemia & Preterm birth complications \\
\hline Stroke & diabetes \\
\hline Road injury & osteoarthritis \\
\hline
\end{tabular}

Fig. 2 Cause of DALYs for female, all age, Iran, 1990-2010 
HIV (PLWH) is estimated to increase from 43,000 in 2006 to 110,000 in 2016. According to the 2014 UNAIDS report, the number of male PLWH will increase by $60.4 \%$ by 2016 , while this rate for female PLWH is estimated to surge by $546 \%$. The third wave of transmission has provoked an increasing trend of HIV among Iranian females; the rate of HIV is $4.5 \%$ for female sex workers [22]. Based on a study done in 2014, the prevalence of sexually transmitted infections [23] associated with symptoms in women (39.9\%) is more than double that of men (17.6\%) [24]. Furthermore, genital ulcers in Iranian females are estimated to be $4 \%$ while in males it is less than $0.4 \%$ [25]. Nasirian et al. showed that $29.7 \%$ of men had experienced at least one STIs-associated symptom during the year prior to the study, while this rate was $81.8 \%$ for women [24]. Giardiasis is the most prevalent parasitic infection in Iran, and studies showed a higher prevalence in males $(15.1 \%)$ than in females (13.9 \%). Listeriosis is another infectious disease common among Iranian females, seen in $36 \%$ of women with a history of spontaneous abortion and $18 \%$ of those with normal full-term deliveries [26].

Maternal health: Maternal mortality per 100,000 live births in Iran has shown a diminishing trend over the past decade (Fig. 3).This is evidenced by a reduction in the maternal mortality rate from 83 to 23 per 100,000 live births between 1990 and 2013, which varied between different provinces in
Iran [27, 28]. Undoubtedly, there was no even distribution in maternal mortality rates across the country as manifested by the unfavorable conditions found in border provinces $(\mathrm{SD}=19.2)$ $[29,30]$. Studies have shown that $90 \%$ of the maternal mortality rate is related to defective emergency midwifery services. Of these, $73 \%$ was due to poor service quality and $25 \%$ was associated with unavailable facilities; $27 \%$ mortality due to hemorrhage has remained of topmost concern over the past two decades. All criteria associated with mothers' health have been improved over the past 20 years except for the rate of cesarean delivery [31].

2) Mental health indicators

Psychiatry and depressive disorders: Studies have shown that mental health indicators in Iran show that men are in better condition than women. Psychological disorders, particularly depressive disorders among women's burden of disease, ranked second in 2003 and first in 2011. The most prevalent diseases among women were anxiety (19.4\%) and mood disorders (17.3 \%) [32]. One noteworthy aspect in the area of mental health is the increasing trend of suicide and suicidal attempts in Iran that varies in relation to gender [33]. Although the rate of committed suicide is greater in men than in women, there is a higher frequency of suicide attempts among Iranian women, a situation showing an increasing trend in recent years [34]. Violence and family disputes are among the most important reasons for attempted

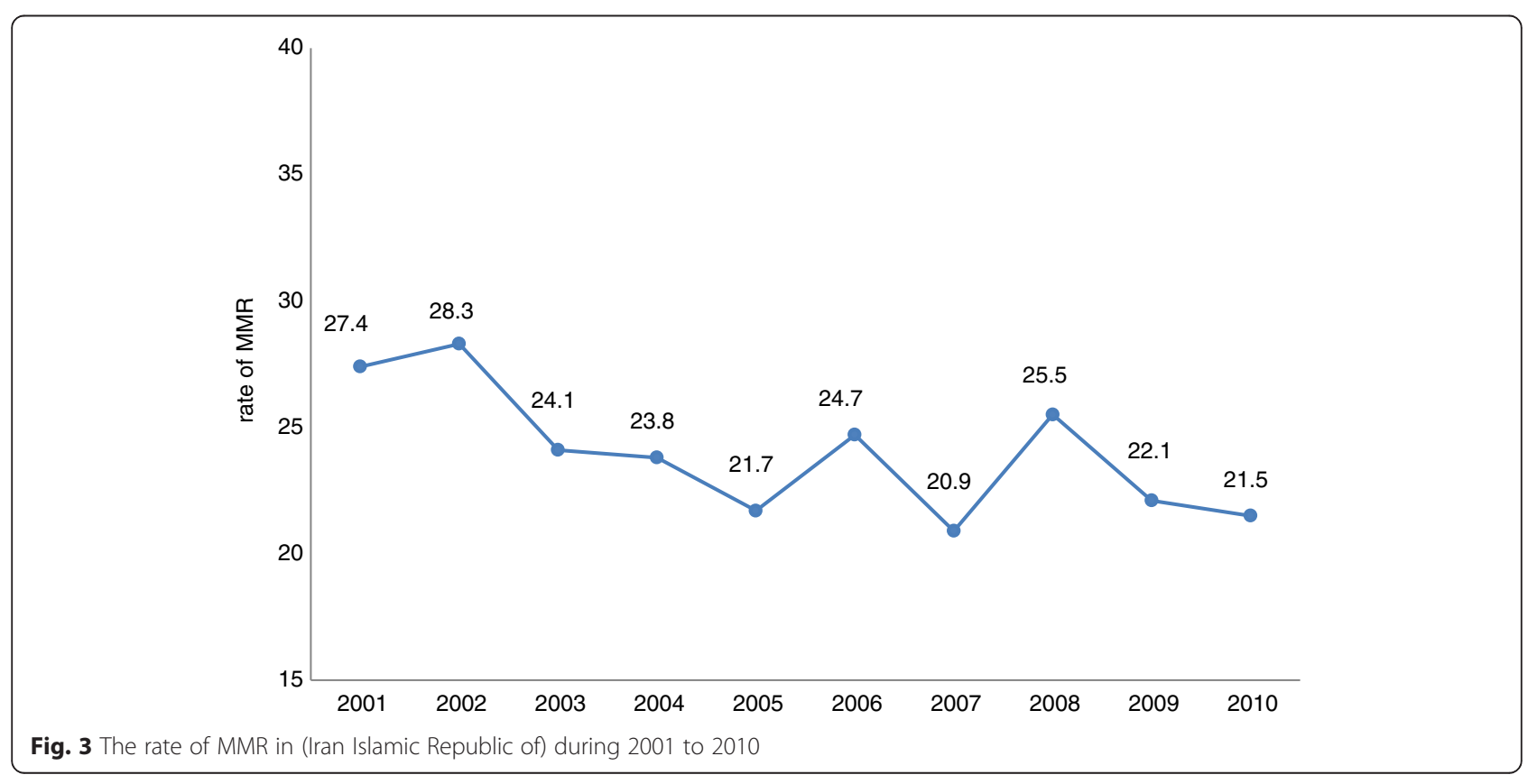


suicides, especially among married women [35]. A point worthy of note is the in homogeneity in women's suicide rates at provincial levels; the rate of failed and successful suicide attempts in women in some provinces, especially western provinces, has become a matter of grave concern. The highest rate of suicide is reported among women in Ilam province where it is 18.7 times the number of suicides among Iranian women and 14.6 times the total number of suicide attempts across Iran [36]. Moreover, $27 \%$ of all suicides in Iran were caused by self-immolation; $71 \%$ of such cases involved women [37].

3) Social health indicators

Gender Gap Index: According to the annual reports of the United Nations, the gender gap index (GGI) has been underlined as an important determinant of human development and an indicator that more explicitly calls attention to women's problems. This index considers gender gap from four aspects: economic participation and opportunity, educational attainment, health and survival, and political empowerment [38]. In regard to this criterion (shown in Table 1), the latest United Nation's report in 2013 ranked Iran 130th among 136 countries in GGI (score $=0.584$ ). Iran's GGI had not followed a consistent trend over the given years, changing from 0.622 in 2000 to 0.584 in 2013 and having 0.0039 as the score for this criterion. On the other hand, $62.1 \%$ of adult women accessed a secondary education or higher compared to their male counterparts [39]. In regard to participation in the job market, $16.4 \%$ and $72.5 \%$ of opportunities are assigned to females and males, respectively [38].

According to the 2013 census, the unemployment rate of Iranians 10 years old or older was $10.5 \%$, and this rate was doubled in females compared to males (18.95\% vs. $9.1 \%)$. The highest rate of unemployment in young people was found in university graduates (37\%) involving $29 \%$ and $48 \%$ of men and women, respectively.

Unemployment rates differed in various provinces. The rate of economic cooperation by women in Iran has shown an increasing trend relative to men in recent years. This was shown by an $8.15 \%$ economic cooperation rate of women in 1990 compared to $16.4 \%$ in 2011 [40].

Basic education is considered an important indicator of empowerment [41]. Iran has witnessed a very rapid growth in literacy during recent years, shown by $28 \%$ to $96 \%$ literacy rates among men and $10 \%$ to $97 \%$ in young women. Women outnumbered men in entering colleges and Iranian universities; this has shown a growth rate of $6.1 \%$ during the period 2006 to 2011. In this context, there are in homogeneities at provincial levels. For instance, the literacy rate of young women is the highest (near $100 \%$ ) in Semnan, a middle socio-economic province, compared to Sistan Baluchistan province which has $68.85 \%$ literacy [42]. Another important point was the differences existing between literacy rates in young women living in urban and rural areas, where $5 \%$ of such difference (98 and $93 \%$, respectively) is still noticeable [43].

Another gender-related problem in Iran is female heads of household which constitute at least 5.2 million or the equivalent of $12 \%$ of Iranian households. This rate has shown an increasing rate of $72 \%$ over the last 15 years [44]. Economically speaking, female heads of household are more vulnerable than their male counterparts; $43 \%$ of women in this category belong to the two lowest income deciles, whereas men as heads of household constitute only $16 \%$ of this group. The highest rate of breadwinner women (64\%) lived in Sistan-

Baluchistan province. Moreover, $9.7 \%$ of female

Table 1 Iran ranks and scores during 2000-2013 based on Gender Gap Index

\begin{tabular}{|c|c|c|c|c|c|c|c|c|c|c|}
\hline & \multicolumn{2}{|c|}{ Overall } & \multicolumn{2}{|c|}{$\begin{array}{l}\text { Economic } \\
\text { participation }\end{array}$} & \multicolumn{2}{|c|}{$\begin{array}{l}\text { Educational } \\
\text { attainment }\end{array}$} & \multicolumn{2}{|c|}{$\begin{array}{l}\text { Health and } \\
\text { survival }\end{array}$} & \multicolumn{2}{|c|}{$\begin{array}{l}\text { Political } \\
\text { Empowerment }\end{array}$} \\
\hline & Rank & Score & Rank & Score & Rank & Score & Rank & Score & Rank & Score \\
\hline Gender Gap Index 2013 (out of 136 countries) & 130 & 0.584 & 130 & 0.365 & 98 & 0.965 & 87 & 0.971 & 129 & 0.035 \\
\hline Gender Gap Index 2012 (out of 135 countries) & 127 & 0.593 & 130 & 0.412 & 101 & 0.953 & 87 & 0.971 & 126 & 0.035 \\
\hline Gender Gap Index 2011 (out of 135 countries) & 125 & 0.589 & 125 & 0.444 & 105 & 0.925 & 85 & 0.971 & 130 & 0.017 \\
\hline Gender Gap Index 2010 (out of 134 countries) & 123 & 0.593 & 125 & 0.426 & 96 & 0.959 & 83 & 0.971 & 129 & 0.017 \\
\hline Gender Gap Index 2009 (out of 134 countries) & 128 & 0.584 & 131 & 0.377 & 96 & 0.964 & 63 & 0.978 & 132 & 0.017 \\
\hline Gender Gap Index 2008 (out of 130 countries) & 116 & 0.602 & 118 & 0.449 & 92 & 0.965 & 60 & 0.978 & 128 & 0.017 \\
\hline Gender Gap Index 2007 (out of 128 countries) & 118 & 0.590 & 123 & 0.395 & 90 & 0.958 & 58 & 0.978 & 122 & 0.031 \\
\hline Gender Gap Index 2006 (out of 115 countries) & 108 & 0.580 & 113 & 0.359 & 80 & 0.954 & 52 & 0.978 & 109 & 0.031 \\
\hline
\end{tabular}


heads of household suffer from disability and psycho-somatic disorders, and $30 \%$ are unable to work because of problems associated with their poor health status [45]. With respect to gender-related poverty, destitution is more pronounced among female household heads than male breadwinners (0.51\% vs. $0.41 \%$ ) [46].

Women and social violence: Despite the recently increasing number of women detained for committing various offenses, only $4.48 \%$ of prisoners with criminal offenses constitute women. As for cooperation between the two genders in committing violent crimes (murder), the ratio of women to men is 1:9 [36]. Generally, statistical analyses have shown a wide spectrum of violence toward women in families, ranging from $17.5 \%$ of pregnant women in Khorasan Razavi to $93.6 \%$ of women in Mazandaran province [47]. The results of inter-provincial studies show a generally high prevalence (2.34 DALY) of violence against women in Iranian families, but the prevalence of violence against women was lowest in Tehran province. Studies have also shown that increasing violence is directly related to rising age in women [48]. However, there is an inverse relationship between education levels, especially a university education, and the prevalence of violence. In addition, there is remarkably less violence against working women than housewives [47].

Studies have shown that the rate of female genital mutilation (FGM) in some ethnicities of Iran is more than $60 \%$. Pashaei et al. showed that keeping with tradition, cleanliness, religious recommendations, and control of sexual desire were the main reasons for performing FGM. One noticeable point is that less than $3 \%$ of respondents named religion as the reason for continuing FGM to the next generation, a tradition which is inversely related to the level of education [49].

\section{Discussion}

Despite the promising trend of women's health in Iran over the past three decades, there is still a difference between women and men with respect to mental, physical, and social health. According to the World Development Report in 2012, women in developing nations, unlike those in developed countries, experience greater mortality rates than men [50]. Gender is a critical determinant for health status in many societies and is rooted in social, cultural, political, and health system-related factors [51-53]. Similar to Iranian females, the global burden of diseases also shows that women aged 15 to 65 years lose more healthy life to disability than men. In spite of this fact, disability has been almost neglected as a central policy priority during the era of the Millennium Development Goals (MDG5) [54].

The nearly $75 \%$ decrease in Iran's maternal mortality (from 83 to $23 \%$ ) from 1990 to 2013 is a remarkable achievement in women's health which correlates with MDG5 goals and is much higher than the global trend $(22 \%)[55,56]$. There is a correlation between the Human Development Index (HDI) and the socio-economic situation of Iranian females. In Sistan -Baluchestan with an HDI of 0.58 , maternal mortality is $53.67 \%$, a rate much higher than that of Tehran province which has HDI 0.78 and maternal mortality of 11.98 [28, 29]. According to a report by Iran's Ministry of Health, more than $50 \%$ of this mortality is still preventable. Hemorrhage, eclampsia, and infection constitute about $50 \%$ of the causes of maternal mortality in Iran. The quality of hospital care, on-time referral of high risk pregnant women, and high rate of caesarian section are considered to be the most important pitfalls of Iran's health system [28].

Mental disorders and domestic violence are other high priority problems among Iranian women. According to a systematic review, social determinants of health have a remarkable relationship with violence not only in Iran, but also on a global scale [57, 58]. According to the 2005 WHO report, the highest rates of violence against women occurred in Bangladesh, Ethiopia, Peru, Tanzania, and to a lesser extent in Japan [59]. According to the last study of burden of disease, non-communicable diseases (NCDs) are a dominant cause of morbidity and disability among Iranian women; the statistics were comparable to many middle income and developed countries [16]. Several factors could account for this phenomenon, of which the two most important are urbanization and change in lifestyle. The ratio of urbanization in Iran has changed from 0.43 to 2.3 between 1980 and 2012. In addition, fast-paced and stressful living conditions [60] have accelerated the nutrition transition that has occurred in Iran during the two past decades [61]. Along with cultural barriers and a shortage of facilities for women's physical activity [62], these can be significant contributing factors for the increasing trend of NCDs among Iranian women. A national survey in 2010 showed that physical inactivity for women was very common (46.3\%) and ranged from 23 to $65 \%$, depending on the residential area [63]. However, cigarette smoking as a risk factor for non-communicable diseases is much less in Iranian females than in Iranian males and close to that of other Persian Gulf countries. It has had a decreasing trend during the past decade, especially among school-aged girls $[64,65]$.

As results of the current study show, Iran is ranked low in the gender gap index. This is in contrast with the fact that $3.1 \%$ of the seats in parliament are assigned to 
women, although there has been a decreasing trend in this indicator from 0.035 to 0.028 from 2000-2012 [39]. On the other hand, women participate actively in many health-related, non-governmental organizations. Around 100,000 women work voluntarily with health systems to expand healthcare coverage for households and to elevate the health education of the people, especially in deprived areas [66].

According to the reports of international organizations, Iranian women's health indicators on average are one of the best in the Eastern Mediterranean region [15]. However, this does not mean that the amount of social participation of women in Iran is acceptable. Considering the gender gap index, Iranian females rank low in political and economic participation, although in access to education and health as well as LE they are ranked better [50]. Based on the gender-related development index, Iran ranked 10th among 19 Islamic countries [38]. Although higher education is most important to elevating the position of women in Iran's society, it can cause scholarly accumulation if not properly applied, resulting in the insufficient participation of women in political and economic spheres [67]. The rate of criminal offenses committed by women has increased proportionately to the rising socio-economic crises and population growth. There has been a steady increase in the number of female offenders compared to men over the past decades, mostly because of drug-related offenses and promiscuity.

\section{Conclusions}

In summary, the challenges to women's health in Iran are rooted in two main areas. The first comprise the social determinants of health which entitle women to equal social positions with men regardless of socio-cultural classification. Women's social values and rights vary in different cultures and locations. For instance, in very traditional societies like some ethnicities in Iran, the social rights of men and women are not equal [68, 69]. Moreover, deprivation that contributes to ill health is common in both developed and developing countries. An evident example is the situation of African Americans in the United States who have lower health indicators than whites because of their socio-economic conditions [70]. The second area refers to the health system and its response to women's needs. Comprehensiveness of a health system is a very important factor for an effective response to the needs of the target population. In this regard, there are two main defects in Iran's health system. Although mental disorders, breast cancer, and violence are placed at the top of the burden of diseases' list among Iranian women $[16,71]$, these priorities have not been seen in the current basic service packages at different levels of Iran's health system. In addition, the imperfect referral system [72] along with fragmentation between different parts of the health system results in a lack of continuity of care, which, in turn, provokes incomplete results for healthcare [69].

Regarding the issues discussed above, which are comparable to many countries, and in order to address the gender chasm, the first strategy could be legislation and the empowerment of women by providing public policy advocacy to protect effectively females against any shape of discrimination and violence, building up the women's Non-Governmental Organization for getting their involvement in female related socio- economic issues, and promoting public awareness about women's right. [71]. The other strategy is Universal Health Coverage which is the most effective remedy for the deficiencies in Iran's current health system, with an emphasis on providing essential and quality services. This reduces the effect of social determinants of health, which demands specific attention to bolster and improve the primary health care.

\section{Competing interests}

The authors declare that they have no competing interests.

\section{Authors' contributions}

$\mathrm{K} . \mathrm{BL}, \mathrm{HJ}$ Conceived and designed the search strategy for this manuscript. MA, $A R, H J$ Contributed search for this manuscript. MA,HJ ,NM, and AR Wrote the manuscript. All authors read and approved the final manuscript.

\section{Acknowledgements}

The authors wish to thank Mr. Tabrizi and Mr. Akbari for their kindly cooperation in critical review of the manuscript. We also express our sincere gratitude to both Health Policy Research Center and Shiraz HIV/AIDS Research Center for their financial support.

\section{Author details}

${ }^{1}$ Shiraz HIV/AIDS Research Center, Shiraz University of Medical Sciences, Shiraz, Iran. ${ }^{2}$ Health Policy Research Center, School of Medicine, Shiraz University of Medical Sciences, Shiraz, IR, Iran. ${ }^{3}$ Guilan Road Trauma Research Center, Guilan University of Medical Science, Guilan, Iran.

Received: 22 June 2015 Accepted: 8 February 2016

Published online: 16 February 2016

\section{References}

1. Wakeich P, Parker B. Mapping research on women and health in northwestern Ontario. Paper submitted for NNEWH's working paper series. 2002.

2. Garcla-Moreno C, Jansen HA, Ellsberg M, Heise L, Watts C. WHO multicountry study on women's health and domestic violence against women: initial results on prevalence, health outcomes and women's responses: World Health Organization; 2005.Available from: http://www.who.int/ gender/violence/who_multicountry_study/summary_report/summary_ report_English2.pdf.

3. Ahmadi B. Women's Health Management: Policy and Research Services Development. Social Welfare. 2012;12(47):29-59. Persion.

4. Organization Worled Health. Women and health: today's evidence tomorrow's agenda: World Health Organization; 2009.Available from:http:// apps.who.int/iris/bitstream/10665/44168/1/9789241563857_eng.pdf.

5. Barbara S. Equity in health. Can Med Assoc J. 2000;162(5):346.

6. Mezey G, Bacchus L, Bewley S, White S. Domestic violence, lifetime trauma and psychological health of childbearing women. BJOG: Obstet Gynecol Int J. 2005;112(2):197-204

7. Plaisier I, De Bruijn J, Smit J, De Graaf R, Ten Have M, Beekman A, et al. Work and family roles and the association with depressive and anxiety disorders: differences between men and women. J Affect Disord. 2008;105(1):63-72. 
8. Kharboush IF, Youssef AA, Makhlouf MM, Zaghloul AA, El-Hamid A, El Masry A. Women health in poor urban settings in Alexandria. J Egypt Public Health Assoc. 2005;80:321-48.

9. Zajacova A. Education, gender, and mortality: Does schooling have the same effect on mortality for men and women in the US? Soc Sci Med. 2006;63(8):2176-90.

10. Pietila I, Rytkonen M. Coping with stress and by stress: Russian men and women talking about transition, stress and health. Soc Sci Med. 2008;66(2):327-38

11. Haghdoost A.A, Safizadeh H, Olyaee Manesh A.R, Beheshtian M,Motlagh M.S Reducing inequalities in health in the Islamic Republic of Iran(1996-2009). 1rd ed. Health Policy Council: Ministry of Health and Medical Education; 2011 (Persian).

12. Malik Kh. Human development report 2013. The rise of the South: Human progress in a diverse world. 2013.

13. Viscomi S, Pastore G, Dama E, Zuccolo L, Pearce N, Merletti F, et al. Life expectancy as an indicator of outcome in follow-up of populationbased cancer registries: the example of childhood leukemia. Ann Oncol. 2006:17(1):167-71.

14. Khosravi A, Rahbar M.R,Motlagh M.A,Kabir M. Indicators of health in the Islamic Republic of Iran Broadcasting. Deputy health -ministry of health and medical education( IRAN)2009.(Persion)

15. Organization WH. Gender and health in the Eastern Mediterranean Region: conceptual and operational 2014. Available from: http://applications.emro. who.int/dsaf/dsa720.pdf?ua=1.

16. Naghavi M, Abolhassani F, Pourmalek F, Lakeh MM, Jafari N, Vaseghi S, et al. The burden of disease and injury in Iran 2003. Popul Health Metr. 2009;7(1):9

17. Malekzade R. Global Burden of Disease Study 2010: A Real Advance in Global Descriptive Epidemiology: Perspective For Developing Countries. Arch Iran Med. 2014:17:304-42. Persion.

18. Non-Communicable Disease Risk Factor. Islamic Republic of IRAN - Ministry of Health \& Medical Education. 2009. http://www.ncdinfobase.ir/english. Accessed 21 oct 2009.(Persion)

19. situation analysis of Ageing in the I.R.Iran. UNFPA in iran, 2014. Available from:http://iran.unfpa.org/Four-Reports-English/ Population\%20Ageing\%20in\%20l.\%20R.\%20lran.pdf.

20. Shirazi M, Sahaf R, Sarmadi M. Study of Health and social indicators of elderly women in Iran. Iran J Ageing. 2012;6:66-87. Persian.

21. Tajvar M, Montazeri A. Determinants of health-related quality of life in elderly in Tehran, Iran. BMC Public Health. 2008;8(823):1-8.

22. The Gap Report. UNAIDS Report,2014. Available from: http://www.unaids. org/sites/default/files/media_asset/UNAIDS_Gap_report_en.pdf

23. Nasirian M, Karamouzian M, Kamali K, Nabipour AR, Maghsoodi A, Nikaeen $\mathrm{R}$, et al. Care Seeking Patterns of STIs-Associated Symptoms in Iran: Findings of a Population-Based Survey. Int J Health Policy Manag 2015;5(1): 5-11.

24. Nasirian M, Baneshi MR, Kamali K, Haghdoost AA, Sedaghat A, Poor ZR, et al. Population-based survey on STI-associated symptoms and health-seeking behaviours among Iranian adults. Sex Transm Infect. 2015:sextrans-2015-052060.

25. Nasirian M, Baneshi MR, Kamali K, Haghdoost AA. Estimation of Prevalence and Incidence of Sexually Transmitted Infections in Iran; A model-based approach. J Res health sci. 2015;15:168-74.

26. Askarian M, Mansour Ghanaie R, Karimi A, Habibzadeh F. Infectious diseases in Iran: a bird's eye view. Clin Microbiol Infect. 2012;18(11):1081-8.

27. Maternal mortality in 1990-2013. Available from: http://www.cepal.org/oig/ noticias/noticias/4/52864/Trends_in_Maternal_Mortality__ 1990 to 2013.pdf

28. Zolala F, Heidari F, Afshar N, Haghdoost AA. Exploring maternal mortality in relation to socioeconomic factors in Iran. Singapore Med J. 2012;53(10):684.

29. Tajik P, Nedjat S, Afshar NE, Changizi N, Yazdizadeh B, Azemikhah A, et al. Inequality in maternal mortality in Iran: an ecologic study. Int J Prev Med. 2012;3(2):116.

30. Najmeh Maharlouei M, Zeinab Zakeri M, Ezat Mazloomi B, Kamran Bagheri Lankarani M. Maternal mortality rate in Fars Province: trends and associated factors in a community-based survey. Arch Iran Med. 2012;15(1):14.

31. Khabiri R, Elahi E1, Khodayari E,Rashidian A. Maternal Health Care based on Iran' Multiple Indicator Demographic and Health Survey (IrMIDHS)-2010. J Health Syst Res. 2014;1(17): 67-77.

32. Noorbala A, Yazdi SB, Yasamy M, Mohammad K. Mental health survey of the adult population in Iran. BJPsych international. 2004;184(1):70-3.

33. Rahimi-Movaghar A, Amin-Esmaeili M, Sharifi V, Hajebi A, Radgoodarzi R, Hefazi M, et al. Iranian Mental Health Survey: Design and Field Proced. Iran J Psychiatry. 2014;9(2):96. Persion.
34. Ghafarian Shirazi HR, Hosseini M, Zoladl M, Malekzadeh M, Momeninejad K, Noorian M, et al. Suicide in the Islamic Republic of Iran: an integrated analysis from 1981 to 2007. East Mediterr Health J. 2012;18(6):607-13.

35. Memari A, Khosravi K, Goodarzi Z. Causes of suicide in married women. Iran J Nurs Midwifery Res. 2006;1:47-53. Persian.

36. Abdolhossainzade R. Report on the iran social situation (2001-2009). 2rd ed. Rahman Institute; 2013. (Persian)

37. Yoosofi J. The Study of Factors Affecting of Self-Burning among Women. J Health Syst Res 2013. 2013;9(7):672-81. Persian.

38. The Gender Inequality Index - Human Development Reports. December2010, Available from: http://hdr.undp.org/sites/default/files/hdrp_2010_46.pdf.

39. Bekhouch $Y$, Hausmann R, Tyson L, Zahidi S. The global gender gap report 2013. Geneva: World Economic Forum; 2013.

40. Shojai Z. Social Analysis of the Status of Women. 1rd ed .Center for Strategic Research, Expediency Council: 2008. (Persian)

41. Basic Education for Empowerment of the Poor. UNESCO1998. Available from: http://unesdoc.unesco.org/images/0011/001192/119268eo.pdf.

42. Amini K. women change indexes and girls education in iran(1996-2006). 1 rd ed. Office of Social Studies, 2007. (Persian).

43. Situation analysis of youth in the I.R.Iran. UNFPA iran: 2014.Available from: http://iran.unfpa.org/Youth_One\%20Pager.pdf.

44. situation analysis of female - headed households in the I.R.iran. UNFPA in iran: 2014.Available from: http://iran.unfpa.org/FHH-r.pdf.

45. Eftekhari N, Rostami M, Khosravi A. The socio-economic situation of female heads and poor heads of households in rural Iran. J Fam Res. 2013:8(2):6-15. Persian.

46. Mohammadi-Nasrabadi F, Abdolahi M, Ghodsi D, Hoshiar-Rad A, Rezvani V Ghafarpour M, et al. Do Iranian Female-headed Households Have Lower Socio-economic and Nutritional Status Compared to Male-headed ones? J Nutr Food Sci. 2015;2(2):13-22.

47. Vameghi M, Sajaddi H. Domestic violence in Iran- review Article (2001-2008). J Soc Welf. 2013;13(50): 37-70. (Persian).

48. Raisi T. The Roots of Violence Against Women in the Family. J Fam Res. 2012:8(1):7-18. Persian.

49. Pashaei T. Related factors of female genital mutilation (FGM) in Ravansar (Iran). J Womens Health Care 2012:1(2):1-3

50. World development report 2012, Gender Equality and Development. Available at: http://siteresources.worldbank.org/INTWDR2012/Resources/ 7778105-1299699968583/7786210-1315936222006/Complete-Report.pdf

51. Yu M-Y, Sarri R. Women's health status and gender inequality in China. Soc Sci Med. 1997:45(12):1885-98.

52. Merzel C. Gender differences in health care access indicators in an urban, low-income community. Am J Public Health. 2000;90(6):909.

53. Behrman JR. Intrahousehold allocation of nutrients in rural India: Are boys favored? Do parents exhibit inequality aversion? Oxf Econ Pap. 1988;40:32-54.

54. Horton R. GBD 2010: understanding disease, injury, and risk. Lancet. 2012; 380(9859):2053-4.

55. Horton R, Phumaphi J. Women, children, and adolescents: the post-2015 agenda. Lancet. 4014:384(9949):1159.

56. World health statistic 2014, Part 3, Global health indicators. Available at: http://apps.who.int/iris/bitstream/10665/112738/1/9789240692671_eng.pdf.

57. Davoodi MR, Ahamdzadeh M, Nojoomi M. Risk factors and protecting factors of domestic violence against women in eastern Mediterranean countries: a systematic review and meta-analysis. Iran J Psychiatry Clin Psychol. 2013:18(4):261-75.

58. Organization WH. Global and regional estimates of violence against women: prevalence and health effects of intimate partner violence and non-partner sexual violence: World Health Organization; 2013.Available from: http://apps. who.int/iris/bitstream/10665/85239/1/9789241564625_eng.pdf?ua=1.

59. Organization WH. WHO multi-country study on women's health and domestic violence against women: summary report of initial results on prevalence, health outcomes and women's responses. 2005.

60. Srivastava K. Urbanization and mental health. Industrial psychiatry journal. 2009:18(2):75

61. Ghassemi H, Harrison G, Mohammad K. An accelerated nutrition transition in Iran. Public Health Nutr. 2002:5(1a):149-55.

62. Vahedian M, Alinia A, Attarzadeh R, Esmaeeli H. Assessment of Physical Activity Among Female Students of Tonekabon-Iran Based on Transtheoretical Model. Thrita. 2012;2(2):127-32.

63. Esteghamati A, Khalilzadeh O, Rashidi A, Kamgar M, Meysamie A, Abbasi M. Physical activity in Iran: results of the third national surveillance of risk 
factors of non-communicable diseases (SuRFNCD-2007). J Phys Act Health. 2011;8(1):27-35

64. Amin-Esmaeili M, Rahimi-Movaghar A, Yunesian M, Sahimi-Izadian E, Moinolghorabaei M. Trend of smoking among students of Tehran University of Medical Sciences: results from four consecutive surveys from 2006 to 2009. Med J Islam Repub Iran (MJIRI). 2013;27(4):168-78

65. Halimi L, Haghdoost AA, Alizadeh SM. Prevalence of cigarette smoking among Iranian women: a systematic review and meta-analysis. Med J Islam Repub Iran. 2013;27(3):132

66. Behdjat H, Rifkin S, Tarin E, Sheikh M. A new role for Women Health Volunteers in urban Islamic Republic of Iran. East Mediterr Health J. 2009;15(5):1165

67. Majmai E. Human development, gender and higher education in Islamic countries (with emphasis on Iran's society). Rahyaft j. 2012;51:29-40. Persian.

68. Roostaee F, Roostaee J, Mohammadi H, Donyavi B, Keykhaie R, Sharifi-Rad J, et al. Estimation of life expectancy in Sistan and Baluchestan province. Iran Int J Res Med Sci. 2014;2(3):1035-9.

69. Ahmadi B , Alimohammadian M. Women, s health in iran:issues and challenge. Payesh J. 2012;11(1):127-137 (Persian).

70. Joulaei H, Lankarani KB, Shahbazi M. Iranian and American health professionals working together to address health disparities in Mississippi Delta based on Iran's Health House model. Arch Iran Med. 2012;15(6):378.

71. Sachs JD, MCArthur JW. The millennium project: a plan for meeting the millennium development goals. Lancet. 2005;365(9456):347-53.

72. Eskandari $\mathrm{M}, \mathrm{Abbaszadeh} \mathrm{A}$, Borhani $\mathrm{F}$. Barriers of referral system to health care provision in rural societies in Iran. J Caring Sci. 2013;2(3):229-36.

\section{Submit your next manuscript to BioMed Central} and we will help you at every step:

- We accept pre-submission inquiries

- Our selector tool helps you to find the most relevant journal

- We provide round the clock customer support

- Convenient online submission

- Thorough peer review

- Inclusion in PubMed and all major indexing services

- Maximum visibility for your research

Submit your manuscript at www.biomedcentral.com/submit
Biomed Central 